\title{
Diabetic ketoacidosis at diagnosis in Austrian children in 1989-2008: a population-based analysis
}

\author{
E. Schober • B. Rami • T. Waldhoer • \\ on behalf of the Austrian Diabetes Incidence Study \\ Group
}

Received: 15 September 2009 / Accepted: 3 February 2010 /Published online: 7 March 2010

(C) Springer-Verlag 2010

\begin{abstract}
Aim The aim of the study was to analyse the prevalence of diabetic onset ketoacidosis (DKA) during a period of 20 years (1989-2008) on a population basis in the whole of Austria. Methods A prospective population-based incidence study (1989-2008) was performed. The registered data set comprised blood glucose, $\mathrm{pH}$, ketonuria and clinical symptoms of DKA at manifestation. DKA was defined as $\mathrm{pH}<7.3$ and severe DKA as $\mathrm{pH}<7.1$. Time trends were estimated using linear regression models.

Results During the study period, 3331 children $<15$ years of age (1,797 boys and 1,534 girls) were registered with newly diagnosed type 1 diabetes. Of these, 1,238 (37.2\%) presented with DKA, $855(25.7 \%)$ had a mild and 383 $(11.5 \%)$ a severe form, and one patient died at onset. DKA frequency was negatively associated with age at onset $(p<$ 0.0001 ). In children $<2$ years the prevalence was $60 \%$, with a higher risk for girls $(70 \%$ vs $54 \%$ for boys, $p<0.05$ ). Despite a significant increase in diabetes incidence in Austria during the observation period from 8.4 to 18.4 / $100,000(p<0.0001)$, no significant change in the prevalence of DKA at manifestation was observed.

Conclusions The overall frequency of DKA in children with newly diagnosed type 1 diabetes in Austria is high and has not changed during the last 20 years despite a clear increase in the manifestation rate. In particular, children less than 2 years of age have a high risk of DKA at onset.
\end{abstract}

E. Schober $(\bowtie) \cdot$ B. Rami

Department of Pediatrics, Medical University of Vienna,

Währinger Gürtel 18-20,

1090 Vienna, Austria

e-mail: edith.schober@meduniwien.ac.at

T. Waldhoer

Department of Epidemiology, Center of Public Health,

Medical University of Vienna,

Vienna, Austria
Keywords Austria $\cdot$ Children · Diabetes manifestation . Diabetic ketoacidosis · Time trend - Type 1 diabetes mellitus
Abbreviations
DKA Diabetic ketoacidosis
SDS Standard deviation score $(z$ score $)$

\section{Introduction}

Diabetic ketoacidosis (DKA) is a life-threatening complication of type 1 diabetes and is present in $15-67 \%$ of children at the time of diagnosis [1-7]. The prevalence of onset DKA varies widely among studies, but most studies have been hospital-based and might therefore have been influenced by the selection bias of hospital referral $[2,4,6]$. There is substantial variation in the incidence rate of type 1 diabetes in children below 15 years in Europe and the regional incidence rate of type 1 diabetes has been reported to be inversely correlated with the prevalence of DKA at diagnosis $[1,8]$.

Some recent investigations have reported a decrease in DKA at onset $[4,6,9]$, which may be due to an increase in medical awareness as a result of high background incidence $[4,6]$, special information campaigns $[9,10]$ or prevention programmes [6]. Because the incidence of childhood type 1 diabetes is increasing in most European countries [11] and numerous epidemiological publications have dealt with this increasing incidence, it might be expected that medical awareness in healthcare professionals should have improved in recent decades.

In Austria, the incidence of type 1 diabetes in children grew by $3 \%$ per year from $8.4 / 100,000$ in 1989 to 18.4 / 100,000 in the year $2008[12,13]$. 
The aim of this study was to analyse the prevalence of onset DKA and the possible time trend during a period of 20 years (1989-2008) on a population basis in the whole of Austria.

\section{Methods}

All patients with newly diagnosed diabetes from 0 to 15 years of age were registered prospectively by a network covering all paediatric hospitals, wards and diabetologists since 1989 (Austrian Diabetes Incidence Study Group). The study was approved by the ethics committee of the Medical University of Vienna. Parents of the patients gave their informed consent. The completeness of case ascertainment was $>93 \%$ and there was uniform completeness of ascertainment over time. Since 1989 the Austrian incidence data have been included in the EURODIAB ACE (Aetiology of childhood diabetes on an epidemiological basis) study and we therefore used the case definition of type 1 diabetes used in that study [11].

The registered data set comprises blood glucose concentration at diagnosis, height and weight at diabetes onset, $\mathrm{pH}$, ketonuria and clinical symptoms of DKA at manifestation (hyperventilation, unconsciousness). DKA was defined as $\mathrm{pH}<7.3$. Mild DKA was defined as $\mathrm{pH}<$ $7.3 \geq 7.1$ and severe DKA as $\mathrm{pH}<7.1$ or clinical signs of severe acidosis, such as hyperventilation or unconsciousness. Additionally, weight and height at diagnosis and postal code of the home addresses at diagnosis were documented.

We estimated a dichotomous (acidosis yes/no) as well as a polychotomous (no, mild, severe) logistic regression model in SAS [14]. Because of missing values (mainly height at onset), only 3,006 observations entered into the regression model. Main effects and interaction effects were estimated. The assumption of proportional odds in the polychotomous regression model was tested with the score test. This assumption states that, apart from a constant, the shape of the association between a risk factor and the two risks (mild and severe acidosis) is the same.

The variables entered were year of diagnosis, age at manifestation, sex, blood glucose, standard deviation score for body mass index (SDS-BMI) and place of residence (nine provinces).

Because of modelling issues, blood glucose was divided by 1,000. Main effects and interaction effects were estimated. The effect of age at manifestation and blood glucose and SDS-BMI were illustrated by plotting estimated prevalence in dependence on the variable of interest and setting the other variables to observed mean values of these variables in the sample.

\section{Results}

During the observation period of 20 years, 3,331 children (1,797 boys and 1,534 girls) under the age of 15 years were diagnosed as having type 1 diabetes, 1,238 (37.2\%) presented with DKA, $855(25.7 \%)$ of them had mild DKA (boys, $25.9 \%$; girls, $25.4 \%$ ) and $383(11.5 \%)$ a severe form (boys, $10.5 \%$; girls, $12.7 \%$ ); one patient (female, age 14.3 years) died at onset from cerebral oedema after $14 \mathrm{~h}$ of treatment.

The frequency of DKA was negatively associated with age at onset (Table 1). In children aged $<2$ years the frequency of DKA was $60 \%(p<0.0001)$. In this age group a trend to more DKA episodes in girls $(70 \%)$ than in boys $(54 \%)$ was observed $(p<0.05)$.

The lowest risk of acidosis was found in children at around 7-8 years of age compared with younger children and adolescents, who showed a significantly higher risk of acidosis (Fig. 1a).

Table 2 shows the results of the dichotomous logistic model.

The polychotomous model showed a significant deviation from the proportional odds assumption $(p=$ 0.007), so that the assumption of proportional odds may be questionable. Except for sex in the dichotomous model, all variables showed a significant $p$ value. In the dichotomous model the effect of sex was not significant (OR $0.87,95 \%$ CI $0.74,1.02, p=0.0837$ ), with a lower prevalence for boys than for girls. In the polychotomous model the effect was very similar (OR $0.82,95 \%$ CI $0.70,0.95$ ) but significant $(p=0.0087)$, again showing a higher risk for girls. The overall effect of the variable province was significant $(p=0.0026)$. ORs and corresponding $95 \%$ confidence intervals with Vienna as reference (OR 1) are shown. The prevalence of DKA in the provinces Vorarlberg and Burgenland was almost half as large as that in Vienna; the Tyrol province showed the highest prevalence, with an OR of 1.1 (Table 3).

Mean blood glucose at diagnosis was significantly higher in children presenting with DKA $(31.3 \pm 15.6$ vs $24.6 \pm 10.2 \mathrm{mmol} / 1, p<0.0001)$. At the beginning of the 1990s, high blood glucose values were associated with a high prevalence of acidosis. This increasing effect of blood glucose attenuated in the years at the end of the study, so that blood glucose did not show a clear effect on the prevalence of DKA. Figure 1b shows the joint effect of the variables year of diagnosis and blood glucose.

Regarding body weight, the lowest prevalence of acidosis occurred in children with SDS-BMI values between 0 and +1 , although the BMI was missing in several cases. The highest prevalence could be seen in distinctly underweight children (SDS-BMI $\leq-1)$.

Despite a significant increase in the incidence of childhood diabetes in Austria $[12,13]$ during the observation period (from 8.4/100,000 to $18.4 / 100,000 ; p<0.0001$ ), 
Table 1 Frequency of DKA and age at manifestation in children with type 1 diabetes in Austria between 1989 and 2008

Data are number of children $(\%)$

\begin{tabular}{llllll}
\hline DKA & \multicolumn{2}{l}{ Age at manifestation (years) } & & \\
\cline { 2 - 6 } & 0 to $<2$ & 2 to $<5$ & 5 to $<10$ & 10 to $<15$ & Total \\
\hline No DKA $(\mathrm{pH} \geq 7.3)$ & $74(40.0 \%)$ & $362(61.4 \%)$ & $804(68.8 \%)$ & $853(61.5 \%)$ & 2,093 \\
Mild DKA $(\mathrm{pH}<7.3 \geq 7.1)$ & $68(36.8 \%)$ & $163(27.6 \%)$ & $262(22.4 \%)$ & $362(26.1 \%)$ & 855 \\
Severe DKA $(\mathrm{pH}<7.1)$ & $43(23.2 \%)$ & $65(11.0 \%)$ & $103(8.8 \%)$ & $172(12.4 \%)$ & 383 \\
Total & 185 & 590 & 1,169 & 1,387 & 3,331 \\
\hline
\end{tabular}

no significant change in the prevalence of DKA at manifestation was observed within the same time period (Fig. 2).

\section{Discussion}

Our study showed that $37.2 \%$ of Austrian children had DKA $(\mathrm{pH}<7.3)$ at diagnosis of type 1 diabetes and $11.4 \%$ presented with severe DKA $(\mathrm{pH}<7.1)$ during the study period of 20 years, with no significant time trend over the years.

The observed prevalence was distinctly higher than the recently published DKA rates in northern Finland [6] and
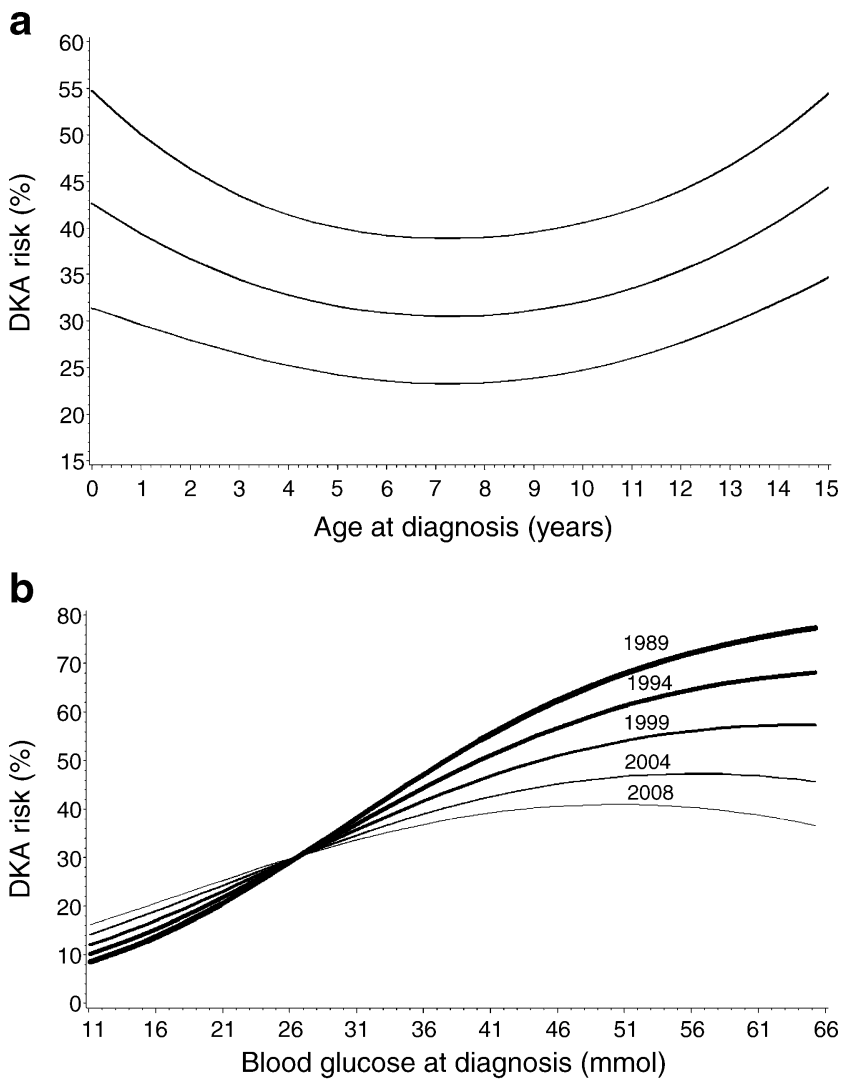

Fig. 1 DKA risk in children with type 1 diabetes $<15$ years of age at manifestation in Austria between 1989 and 2008. a Effect (with 95\% CI) of age at diagnosis on DKA risk. b Effect of blood glucose concentration and year of diagnosis on risk of DKA southern Sweden [4, 8], but similar to those reported for Germany [15], the UK [16] and the USA [7].

In a previous EURODIAB study [1] an inverse relationship between the diabetes incidence rate and the prevalence of DKA at onset of the disease was found, with DKA prevalence rates between 26 and $67 \%$. A possible explanation for this association could be the greater medical awareness of diabetic symptoms in the population, especially family doctors, in high-incidence regions, but another reason might be other environmental differences leading to a more severe and rapid disease presentation.

In Austria the incidence rate doubled during the observation period and several publications [12, 13] have noted not only an Austrian but also a European increase in childhood diabetes [11]. However, we did not observe a decrease in the frequency of mild or severe DKA at manifestation during the last 20 years. This is in contrast to reports from Finland [6] and Italy [9, 10], where clear reductions in the frequency of DKA at diagnosis were reported. During the last 20 years in northern Finland, the prevalence of DKA has fallen from 29.5 to $18.9 \%$. For Finland, the argument of increased medical awareness due to the highest diabetes incidence worldwide may be considered, but additionally the Type 1 Diabetes Prediction

Table 2 Parameter estimates and $p$ values for the dichotomous logistic model in children with type 1 diabetes $<15$ years of age at manifestation in Austria between 1989 and 2008

\begin{tabular}{|c|c|c|}
\hline Parameter & Estimate & $p$ value \\
\hline Intercept & -8.782 & $<0.001$ \\
\hline \multicolumn{3}{|l|}{ Intercept 1 (polychotomous model only) } \\
\hline Year of manifestation & 0.063 & 0.001 \\
\hline Blood glucose concentration & 18.743 & $<0.001$ \\
\hline IA: year of manifestation $\times$ blood glucose & -0.132 & $<0.001$ \\
\hline IA: blood glucose ${ }^{2}$ & -2.423 & $<0.001$ \\
\hline Age at manifestation & -0.160 & 0.001 \\
\hline IA: (age at manifestation $)^{2}$ & 0.011 & $<0.001$ \\
\hline SDS-BMI & -0.078 & 0.063 \\
\hline IA: SDS-BMI ${ }^{2}$ & 0.067 & $<0.001$ \\
\hline Sex & -0.071 & 0.084 \\
\hline Province & - & 0.003 \\
\hline
\end{tabular}

IA, interaction or quadratic effect 
Table 3 ORs, 95\% CI and $p$ values for provincial data for the dichotomous logistic model with Vienna as reference (OR 1)

\begin{tabular}{llll}
\hline Province & OR & $95 \%$ CI & $p$ value \\
\hline Burgenland & 0.53 & $0.34,0.83$ & 0.005 \\
Corinthia & 0.65 & $0.45,0.94$ & 0.023 \\
Lower Austria & 0.90 & $0.70,1.15$ & 0.402 \\
Upper Austria & 0.69 & $0.53,0.89$ & 0.005 \\
Salzburg & 0.81 & $0.55,1.19$ & 0.260 \\
Styria & 0.69 & $0.52,0.91$ & 0.009 \\
Tyrol & 1.10 & $0.79,1.53$ & 0.593 \\
Vorarlberg & 0.65 & $0.42,1.02$ & 0.059 \\
\hline
\end{tabular}

and Prevention (DIPP) project may focus interest on childhood diabetes. The background diabetes incidence in Italy is similar to that in Austria, but a DKA prevention campaign in the province of Parma showed a significant decrease in onset DKA from 78 to $12.5 \%$.

In almost all reports on onset DKA, younger children have the highest risk of presenting with DKA at manifestation $[6-8,17,18]$, indicating that the disease process may be more aggressive in young children and this age group might be more vulnerable to dehydration compared with other age groups. Additionally, the classical diabetic symptoms may be missed in the very young. On the other hand, teenagers are also at risk of DKA at manifestation [6]. Young adolescents may be more secretive about their symptoms and therefore run a higher risk of developing DKA. Like other investigators, we did not observe a significant difference between girls and boys in the whole cohort, with the exception of the youngest age group and

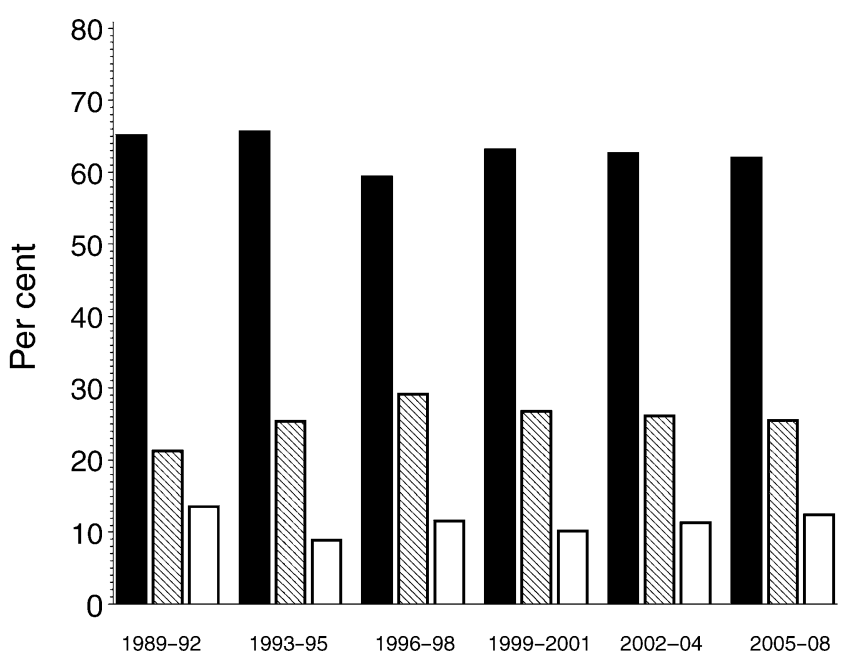

Fig. 2 Temporal trend in DKA rates of children with type 1 diabetes $<15$ years of age at manifestation in Austria between 1989 and 2008. Black columns, no acidosis; shaded columns, mild acidosis $(\mathrm{pH}<7.3 \geq$ 7.1); white columns, severe acidosis $(\mathrm{pH}<7.1)$ for the severe form of DKA, where girls were more at risk than boys.

Patients with DKA presented with relatively high blood glucose concentrations. Especially at the beginning of the 1990s, high blood glucose values led to a high prevalence of acidosis. The effect of blood glucose concentration on the incidence of acidosis decreased in the years towards the end of the study. We have no clear explanation for this finding, but it could be associated with the change in the age at manifestation in our population towards a younger age, when the risk of acidosis is higher even with lower blood glucose values [13]. A recent study in children demonstrated that the blood glucose level was not associated with the clinical severity of DKA [19]. Weight loss before diagnosis is a typical sign of metabolic derangement, with a higher risk of onset DKA. Therefore, the highest prevalence of DKA in children with a SDS-BMI below -1 in our cohort is not surprising.

A shortcoming of our investigation is that the registry contained no data on socioeconomic factors such as family income or parental educational level or on ethnicity on an individual basis, which have been described as factors predisposing to the development of DKA [7, 8, 15, 20-22]. We found an interesting regional difference among Austrian provinces, with the highest risk in Tyrol and Vienna. This finding might be associated with different barriers to a timely diagnosis in these two provinces. In Tyrol, it is mainly one hospital in the centre of the province (Innsbruck) that takes care of diabetic children, so the distance to the hospital in mountainous regions may delay diagnosis. A recent British study reported that a delay in diagnosis doubled the frequency of DKA at onset [16]. A possible explanation for the relatively high frequency of onset DKA in Vienna, where there are several children's hospitals, is the high prevalence of a migration background in diabetic patients in Vienna, leading to barriers to healthcare because of language problems or health beliefs. In Vienna more than $30 \%$ of newborn children have a migration origin, whereas only in 10-20\% have such an origin in the other provinces (Statistics Austria), and in the year 2008, 59\% of newly diagnosed diabetic children in Vienna (University Children's Hospital) had a migrant family background compared with only $22 \%$ in Graz (University Children's Hospital, Styria).

In conclusion, the overall frequency of DKA in children with newly diagnosed type 1 diabetes in Austria is high and has not changed during the last 20 years despite a clear increase in the manifestation rate. In particular, children less than 2 years of age have a high risk of DKA at onset. Efforts such as a nationwide campaign similar to the Parma initiative are needed in order to reduce the rate of onset DKA in Austria, as purely epidemiological publications are an inadequate means of increasing awareness of childhood diabetes in the healthcare system and the population. 
Acknowledgements The study was supported by Novo Nordisk Austria.

Duality of interest The authors declare that there is no duality of interest associated with this manuscript.

\section{Appendix}

Members of the Austrian Diabetes Incidence Study Group: W. Arocker, M. Bauer, F. Baumgartner, M. Borkenstein, B. Bittmann, E. Beran, G. Distlberger, L. Dorninger, J. Fussenegger, E. Fröhlich-Reiterer, M. Fink, G. Gansl, K. H. Guttenberger, F. Häckel, S. Hofer, H. Holzer, C. Holzleitner, C. Jahn, A. Jäger, S. Judmaier, U. Kovac, R. Kovacic, J. Kersak, P. Kitzler, P. Kurnik, G. Kuthan, S. Lindauer, F. Meszaros, J. Mühleder, G. Müller, M. Müllner, M. Neuhauser, R. Niederseer, R. Pieberhofer, R. Paier, C. Prchla, R. Rath, H. Raschbacher, O. Rittinger, T. Rojacher, H. Salzer, P. Schermann, J. Schlager, K. Schmitt, U. Schneider, M. Scholtze, I. Walser, G. Wakolbinger, G. Weinhandl, H. Wutzl.

\section{References}

1. Levy-Marchal C, Patterson CC, Green A, The EURODIAB ACE Study Group (2001) Geographical variation of presentation at diagnosis of type I diabetes in children. Diabetologia 44(Suppl 3): B75-B80

2. Jackson W, Hofman PL, Robinson EM, Elliot RB, Pichler CC, Cutfield WS (2001) The changing presentation of children with newly diagnosed type 1 diabetes mellitus. Pediatr Diabetes 2:154-159

3. Bui ThB, Werther GA, Cameron FJ (2002) Trends in diabetic ketoacidosis in childhood and adolescence: a 15-yr experience. Pediatr Diabetes 3:82-88

4. Samuelsson U, Stenhammar L (2005) Clinical characteristics at onset of Type 1 diabetes in children diagnosed between 1977 and 2001 in the south-east region of Sweden. Diabetes Res Clin Pract 68:49-55

5. Hanas R, Lindgren F, Lindblad B (2007) Diabetic ketoacidosis and cerebral oedema in Sweden - a 2 year paediatric population study. Diabet Med 24:1080-1085

6. Hekkala A, Knip M, Veijola R (2007) Ketoacidosis at diagnosis of type 1 diabetes in children in Northern Finland. Temporal changes over 20 years. Diabetes Care 30:861-866

7. Rewers A, Klingensmith G, Davis C et al (2008) Presence of diabetic ketoacidosis at diagnosis of diabetes mellitus in youth: the Search for Diabetes in Youth Study. Pediatrics 121:e1258e1266

8. Sadauskaite-Kuehne V, Samuelsson U, Jašinskien E et al (2005) Severity at onset of childhood type 1 diabetes in countries with high and low incidence of the condition. Diabetes Res Clin Pract 68:247-254

9. Vanelli M, Chiari G, Costi G, Ghizzoni L, Giacalone T, Chiarelli F (1999) Effectiveness of a prevention program for diabetic ketoacidosis in children. Diabetes Care 22:7-9

10. Vanelli M, Scarabello C, Fainardi V (2008) Available tools for primary ketoacidosis prevention at diabetes diagnosis in children and adolescents. 'The Parma campaign'. Acta Biomed 79:73-78

11. Patterson CC, Dahlquist GG, Gyürüs E, Green A, Soltesz G, the EURODIAB Study Group (2009) Incidence trends for childhood type 1 diabetes in Europe during 1989-2003 and predicted new cases 2005-20: a multicentre prospective registration study. Lancet 373:2027-2033

12. Schober E, Waldhoer T, Rami B, Hofer S, Austrian Diabetes Incidence Study Group (2009) Incidence and time trend of type 1 and type 2 diabetes in Austrian children 1999-2007. J Pediatr 155:190-193.e1

13. Schober E, Rami B, Waldhoer T, Group Austrian Diabetes Incidence Study (2008) Steep increase of incidence of childhood diabetes since 1999 in Austria. Time trend analysis 1979-2005. A nationwide study. Eur J Pediatr 167:293-297

14. SAS/STAT User's Guide, Version 9, NC 27513: SAS Institute, 2002-2003

15. Neu A, Willasch A, St E, Hub R, Ranke MB (2003) Ketoacidosis at onset of type 1 diabetes mellitus in children-frequency and clinical presentation. Pediatr Diabetes 4:77-81

16. Sundaram PCB, Day E, Kirk JMW (2009) Delayed diagnosis in type 1 diabetes mellitus. Arch Dis Child 94:151-152

17. Pinkney JH, Bingley PJ, Sawtell PA, Dunger DB, Gale EAM (1994) Presentation and progress of childhood diabetes mellitus: a prospective population-based study. Diabetologia 37:70-74

18. Quinn M, Fleischmann A, Rosner B, Nigrin DJ, Wolfsdorf JI (2006) Characteristics at diagnosis of type 1 diabetes in children younger than 6 years. J Pediatr 148:366-371

19. Edge JA, Bergomi RY, Murphy NP, Ford-Adams ME, Ong KK, Dunger DB (2006) Conscious level in children with ketoacidosis is related to severity of acidosis and not to blood glucose concentration. Pediatr Diabetes 7:11-15

20. Curtis JR, To T, Muirhead S, Cummings E, Daneman D (2002) Recent trends in hospitalisation for diabetic ketoacidosis in Ontario children. Diabetes Care 25:1591-1596

21. Maniatis AK, Goehrig SH, Gao D, Rewers A, Walravens P, Klingensmith GJ (2005) Increased incidence and severity of diabetic ketoacidosis among uninsured children with newly diagnosed type 1 diabetes mellitus. Pediatr Diabetes 6:79-83

22. Mallare JT, Cordice CC, Ryan BA, Carey DE, Kreitzer PM, Frank GR (2003) Identifying risk factors for the development of diabetic ketoacidosis in new onset type 1 diabetes mellitus. Clin Pediatr (Phila) 42:591-597 